\title{
O CRESCIMENTO URBANO E OS IMPACTOS AMBIENTAIS NA APA DO ITAPIRACÓ, SÃO LUÍS-MA
}

Cláudia Thayse Machado Torres - thaysetorres.eng@gmail.com

Faculdade Pitágoras

Lorena Cristina Silva Sousa - lores321@ hotmail.com

Faculdade Pitágoras

Francisco Wendell Dias Costa - geo.fwcosta@gmail.com

FCT/UNESP campus Presidente Prudente 


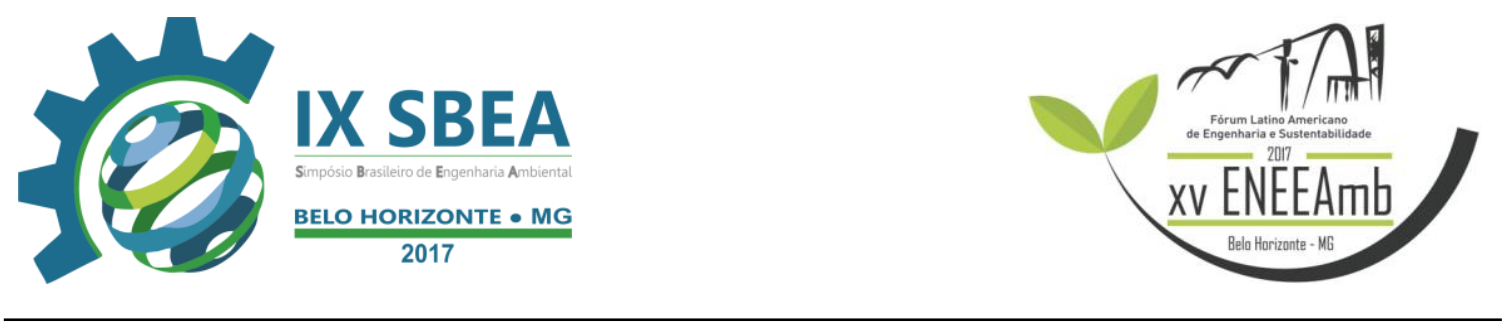

\section{RESUMO}

O objetivo deste trabalho é identificar impactos causados pela ação antrópica na APA do Itapiracó pelo método de matriz de impacto através de dados gerados em estudos preliminares de pesquisa a campo e registro fotográfico, assim como detectar as alterações provocadas em uma escala de 14 anos por imagem de satélite, Google Earth (2003; 2017). Os resultados obtidos permitem inferir que devido estar localizada na área urbana de São Luís-MA tem sido pressionada pelo crescimento dos bairros adjacentes, provocando impactos ambientais na APA, como: o desaparecimento de nascente, desmatamento, retirada de madeira, disposição inadequada de resíduos sólidos de origem doméstica. Para tanto, é possível apontar medidas atenuantes a serem tomadas: proibição do despejo de efluentes na APA, controlar o crescimento dos bairros que se encontram as margens da APA, fiscalizar o desmatamento, etc. É pertinente quantificar os impactos ambientais, corrigindo-os, além de associar a população com ações de educação ambiental na tentativa de proteger essa área.

Palavras-chave: Crescimento Urbano. Área de Proteção Ambiental. Impactos Ambientais.

\section{INTRODUÇÃO/OBJETIVO}

A Constituição Federal (CF) em seu Artigo 225 assegura que a todos o direito ao meio ambiente ecologicamente equilibrado, como condição essencial à sadia qualidade de vida, impondo ao Poder Público e à coletividade o dever de defendê-lo e preservá-lo para as presentes e futuras gerações. Para assegurar a efetividade desse direito, determina ao Poder Público, entre outras obrigações, que crie espaços territoriais e seus componentes a serem especialmente protegidos em todas as unidades da Federação (BRASIL, 1998)

As principais características do crescimento urbano de São Luís são relacionadas aos avanços em direção ao município de São José de Ribamar. Isso propiciou o surgimento de novas áreas urbanas para a implantação de conjuntos populacionais financiados pelo poder público e pela iniciativa privada, mas também, motivou o surgimento de ocupações desordenadas e irregulares de forma horizontal adentrando em áreas protegidas (ARAÚJO, RANGEL, 2012; SANTOS, 2015). 


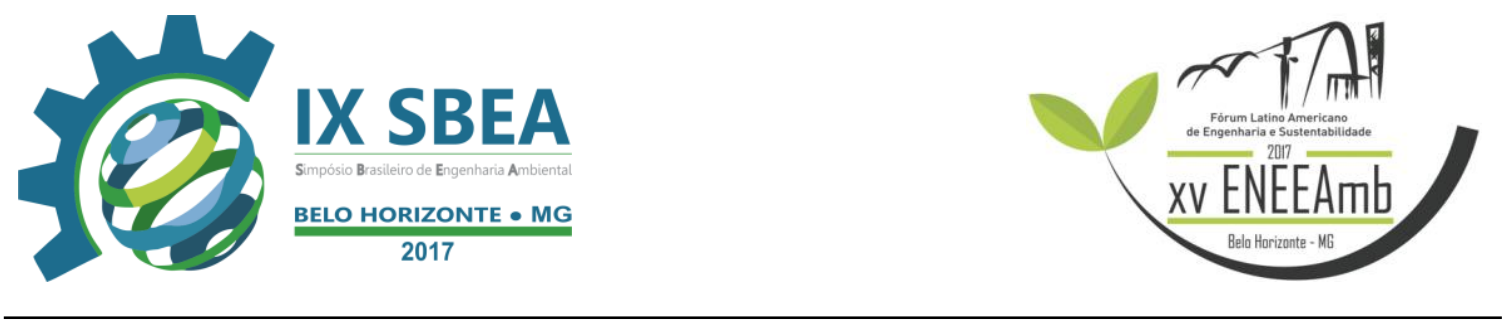

A Área de Proteção Ambiental do Itapiracó criada pelo Decreto Estadual $n^{\circ}$ 15.618 de 23 de junho de 1997, possui extensão territorial de 322 hectares dotada de atributos abióticos, bióticos, estéticos e culturais especialmente importantes para a qualidade de vida e o bem-estar da população, tendo como objetivos básicos proteger a diversidade biológica, disciplinar o processo de ocupação e assegurar a sustentabilidade do uso dos recursos naturais. A área de estudo possui mais de $70 \%$ de cobertura florestal alterada. Devido às alterações causadas pela ação antrópica, existem ocorrências de desaparecimento de nascente, desmatamento, retirada de madeira, disposição inadequada de resíduo sólido de origem doméstica, dentre outros.

Com este trabalho tem como objetivo geral identificar impactos causados pela ação antrópica na APA do Itapiracó utilizando o método de matriz de impacto através de dados gerados em estudos preliminares de pesquisa a campo e registro fotográfico. Tendo como objetivos específicos realizar avaliação preliminar por meio de pesquisa a campo e registro fotográfico e destacar medidas de mitigação a serem tomadas.

\section{METODOLOGIA}

Com o intuito de identificar os impactos ambientais no local, foi realizada uma avaliação preliminar, através de trabalho na área de estudo e registro fotográfico. Também se fez uso de imagens do Google Earth® $(2003$; 2017) para fazer comparação das alterações sofridas nas áreas de estudo. Para melhor avaliação dos impactos, foi utilizado o método de matriz de agregação de impacto ambiental, adotando várias categorias de parâmetros e intensidades desses efeitos, sendo: Classificação: Adversa (AD) ou Benéfica (BE); Incidência: Direto (DIR) ou Indireto (IND); Abrangência: local (LO) ou Regional (REG); Tempo: Passado (PA), Atual (AT) e Futuro (FU); Magnitude: Pequeno (PE); Médio (ME); Grande (GR). Adotadas várias categorias de parâmetro e intensidades desses efeitos, sendo conforme utilizada por (ROCHA, E. C; CANTO, J. L; PEREIRA, P. C, 2005). Além da pesquisa bibliográfica.

\section{RESULTADOS E DISCUSSÃO}


A Área de Proteção Ambiental do Itapiracó está localizada entre os Municípios de São Luís e São José de Ribamar, fazendo limites nos bairros: Conjunto do Parque Vitória ao Norte; Condomínio Itapiracó, ao Sul; Conjunto Ipem Turu, ao Oeste; Conjunto Cohatrac IV e Loteamento Soterra, ao Leste, possuindo vegetação remanescente da Floresta Amazônica. (COSTA, 2008). Está localizada entre as latitudes

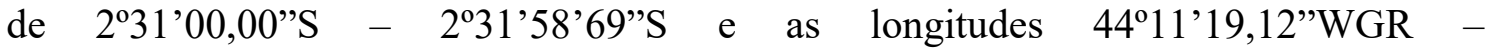
$44^{\circ} 13,15,69^{\prime}$ 'WGR, conforme figura 01 .

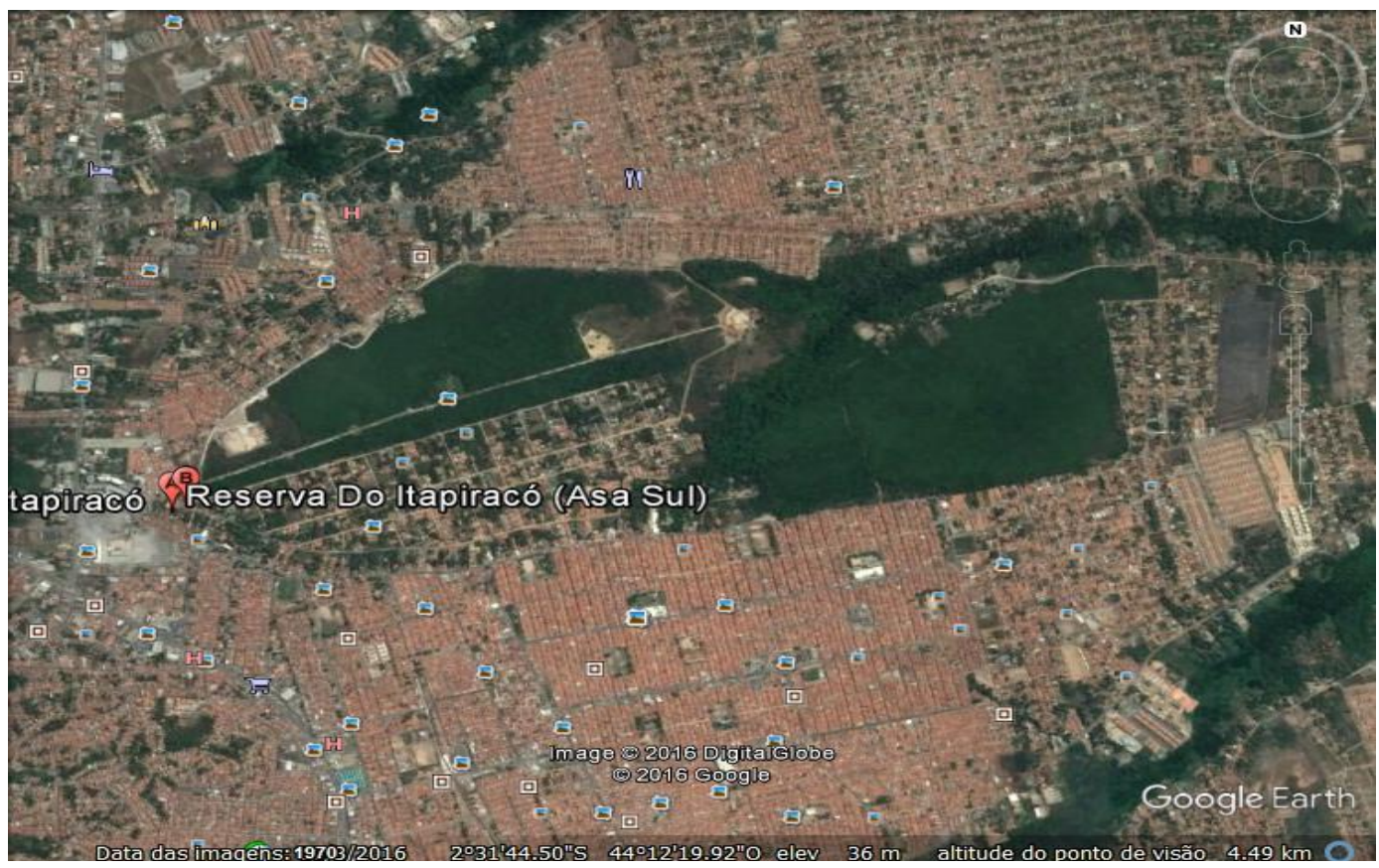

Figura 01: localização da Área de Proteção Ambiental do Itapiracó, São Luís-MA Fonte: Google Earth

Em observação in loco foram identificadas diversas problemáticas, dentre elas: o desmatamento e impermeabilização do solo pela realização de infraestrutura que visam a recreação e lazer, provocando mudanças na biodiversidade com efeito adverso a sua funcionalidade no abastecimento do lençol freático, amenizando da temperatura inibição de enchentes e outras. É constante presenciar moradores jogando resíduos sólidos de origem doméstica e "carroceiros" descarregando de forma inadequada os materiais na área da APA. Em outro local foi identificado um ponto de descarga de efluente in natura das residências em seus arredores. 


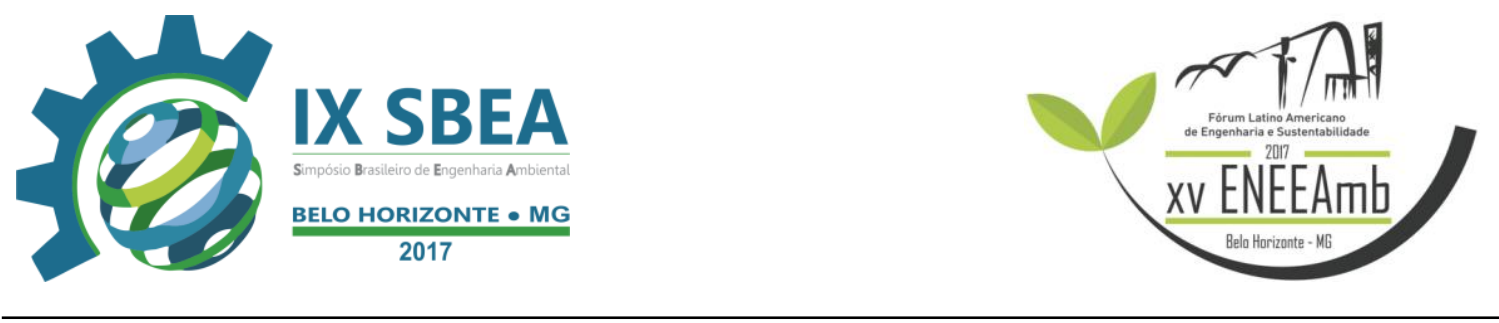

Os resíduos sólidos de origem doméstica podem provenientes da ascensão do escoamento superficial da área urbanizada. Foram encontrados pontos de mata queimada em fase de supressão, assim como toras de madeira cortadas, resultando redução da biodiversidade, degradação do solo, dentre outros (COSTA, 2008). Nas proximidades de processo da área suprimida, havia 3 (três) nascentes sem cobertura para a sua devida proteção, provocado pelo intenso processo de degradação da mata ciliar, o que leva ao carreamento de sedimento resultando em assoreamento do leito do rio.

Os impactos gerados são visíveis e com isso foi feito uma listagem deles sobre os diferentes componentes do ambiente, separados aqui em meio físico, meio biótico e meio antrópico, foi feita uma breve discussão, destacando-se os de maior relevância (Tabela 01).

Tabela 01: Avaliação de Impactos na APA do Itapiracó

Fonte: organizado pelo autor (2017).

\begin{tabular}{|c|c|c|c|c|c|c|c|c|c|c|c|c|c|c|}
\hline \multicolumn{15}{|c|}{ Avaliação de Impacto Ambiental na APA do Itapiracó - São luís -MA } \\
\hline \multirow{2}{*}{\multicolumn{3}{|c|}{ IMPACTOS }} & \multicolumn{2}{|c|}{ Classificação } & \multicolumn{2}{|c|}{ Incidência } & \multicolumn{2}{|c|}{ Abrangência } & \multicolumn{3}{|c|}{ Tempo } & \multicolumn{3}{|c|}{ Magnitude } \\
\hline & & & AD & BE & DIR & IND & LO & REG & PA & AT & FU & PE & ME & GR \\
\hline \multirow{5}{*}{ 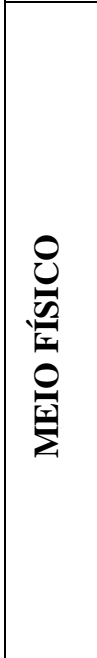 } & \multirow{2}{*}{ 号 } & $\begin{array}{l}\text { Escoamento } \\
\text { Superficial }\end{array}$ & $\mathbf{x}$ & & & $\mathbf{x}$ & $\mathbf{x}$ & & & $\mathbf{x}$ & & & $\mathbf{x}$ & \\
\hline & & $\begin{array}{c}\text { Erosão e } \\
\text { Instabilidade }\end{array}$ & $\mathbf{x}$ & & $\mathbf{x}$ & & $\mathbf{x}$ & & & $\mathbf{x}$ & & & & $\mathbf{x}$ \\
\hline & \multirow{2}{*}{ 苞 } & $\begin{array}{l}\text { Despejo de } \\
\text { Efluentes }\end{array}$ & $\mathbf{x}$ & & & & & $\mathbf{x}$ & $\mathbf{x}$ & & & & & $\mathbf{x}$ \\
\hline & & $\begin{array}{l}\text { Resíduos } \\
\text { Sólidos }\end{array}$ & $\mathbf{x}$ & & $\mathbf{x}$ & & & $\mathbf{x}$ & & $\mathbf{x}$ & & & & $\mathbf{x}$ \\
\hline & 永 & $\begin{array}{c}\text { Material } \\
\text { Particulado } \\
\text { Suspenso }\end{array}$ & $\mathbf{x}$ & & & $\mathbf{x}$ & & $\mathbf{x}$ & $\mathbf{x}$ & & & $\mathbf{x}$ & & \\
\hline$\underbrace{0}_{\substack{0 \\
\sum_{i=1}^{0}}}$ & 点 & $\begin{array}{c}\text { Caça } \\
\text { predatória de } \\
\text { animais } \\
\text { silvestres }\end{array}$ & $\mathbf{x}$ & & $\mathbf{x}$ & & $\mathbf{x}$ & & & $\mathbf{x}$ & & & $\mathbf{x}$ & \\
\hline
\end{tabular}




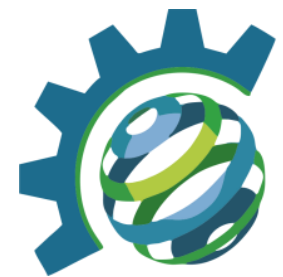

\begin{tabular}{|c|c|c|c|c|c|c|c|c|c|c|c|c|}
\hline & & Mata Ciliar & $\mathbf{x}$ & & $\mathbf{x}$ & & $\mathbf{x}$ & & & $\mathbf{x}$ & & $\mathbf{x}$ \\
\hline & 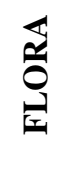 & $\begin{array}{c}\text { Diminuição/ } \\
\text { Perda de } \\
\text { Biodiversidad } \\
\text { e. }\end{array}$ & $\mathbf{x}$ & & $\mathbf{x}$ & & $\mathbf{x}$ & & $\mathbf{x}$ & & & $\mathbf{x}$ \\
\hline & & $\begin{array}{l}\text { Ocupação } \\
\text { Irregular }\end{array}$ & $\mathbf{x}$ & & $\mathbf{x}$ & & & $\mathbf{x}$ & $\mathbf{x}$ & & & $\mathbf{x}$ \\
\hline & & $\begin{array}{c}\text { Recreação e } \\
\text { Lazer na APA }\end{array}$ & & $\mathbf{x}$ & & $\mathbf{x}$ & $\mathbf{x}$ & & $\mathbf{x}$ & & $\mathbf{x}$ & \\
\hline
\end{tabular}

\subsection{Impactos ao Meio Físico}

Foi observado avanço do processo erosivo e um assoreamento do canal do rio, o que pode ter ocorrido devido à descarga de sedimentos que foram jogadas na margem da APA e foi agravado em função dos efeitos do escoamento superficial e da descarga de efluentes.

Figura 02: Assoreamento do canal do rio do Itapiracó, São Luís-MA

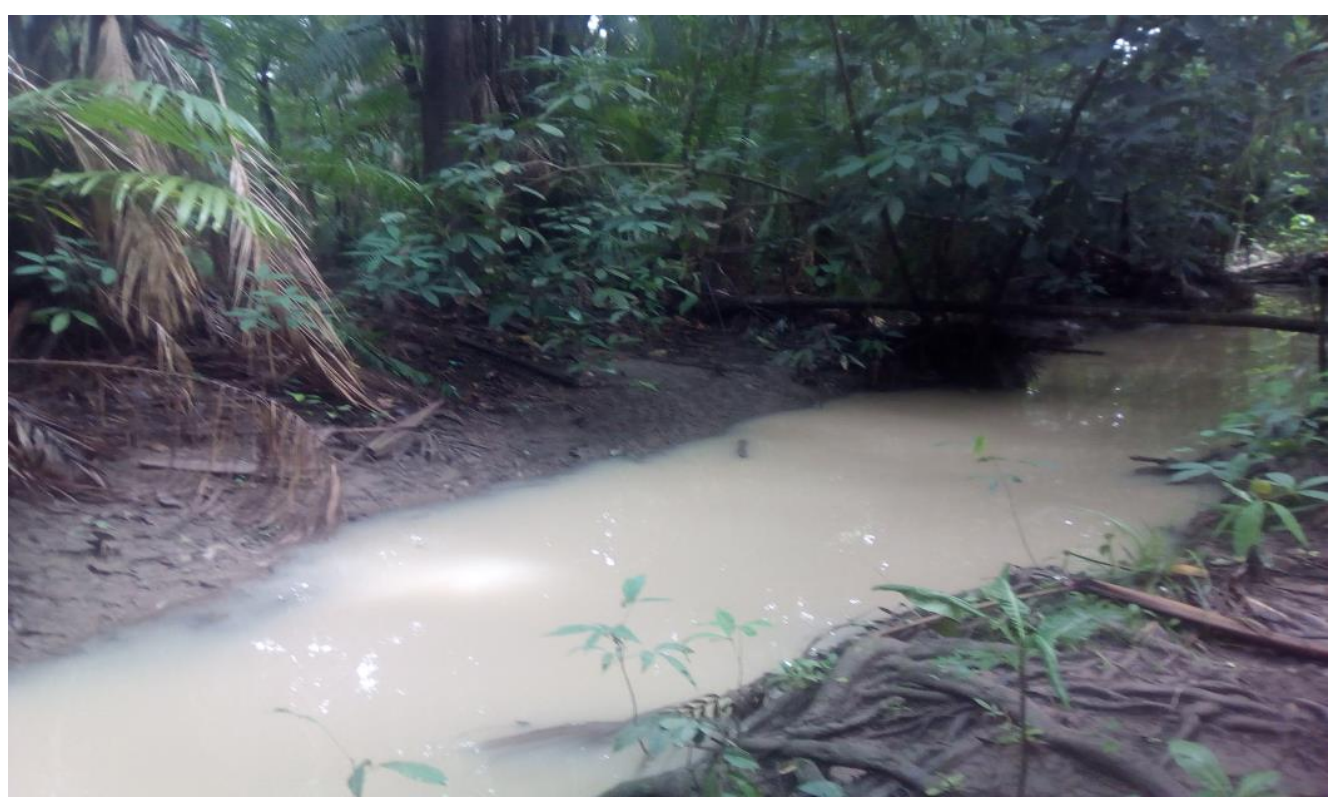

Fonte: Registro de Pesquisa (2017).

\subsection{Impactos do Meio Biótico}


Foi constatada alteração do ecossistema natural, com grande prevalência de resíduos sólidos domésticos (plásticos e latas). Devido ser lançado efluente na APA e resíduos que moradores jogam as margens da Apa, no período de chuva eles são arrastados para dentro do rio, assim, alteram o funcionamento do ecossistema, conforme a figura 03.

Figura 03: Resíduos sólidos na APA do Itapiracó, São Luís-MA

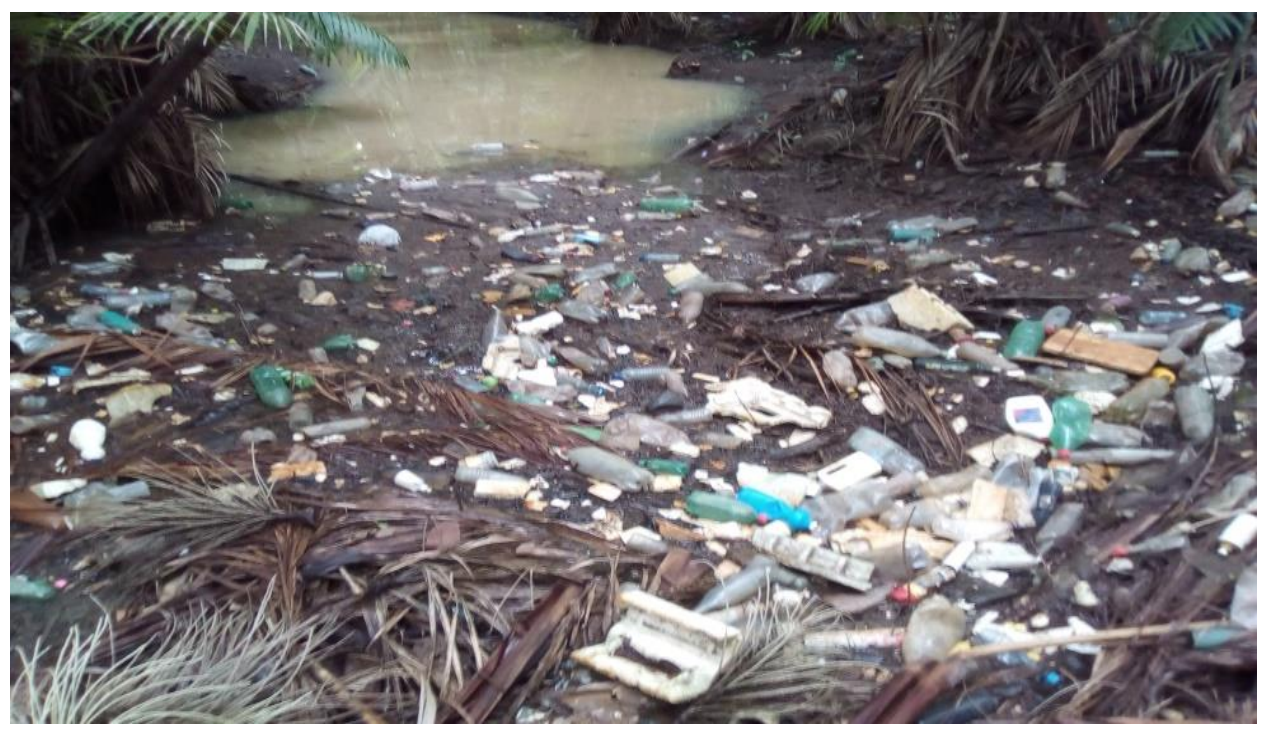

Fonte: Registro de Pesquisa (2017).

\subsection{Impactos Meio Antrópico}

Foi observado que moradores utilizam a área para retirada de madeira e despejo de resíduos, sendo que o certo seria que utilizassem somente com a finalidade de lazer, porém nem todos colaboram com a preservação da APA. (Figuras 04 e 05). 


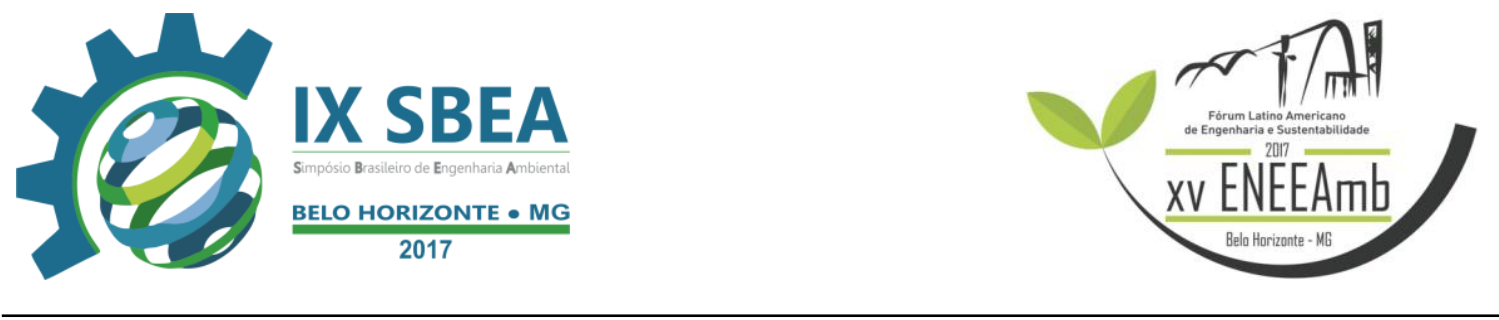

Figura 04 e 05: queimada e retirada de madeira na APA do Itapiracó, São

\section{Luís-MA}
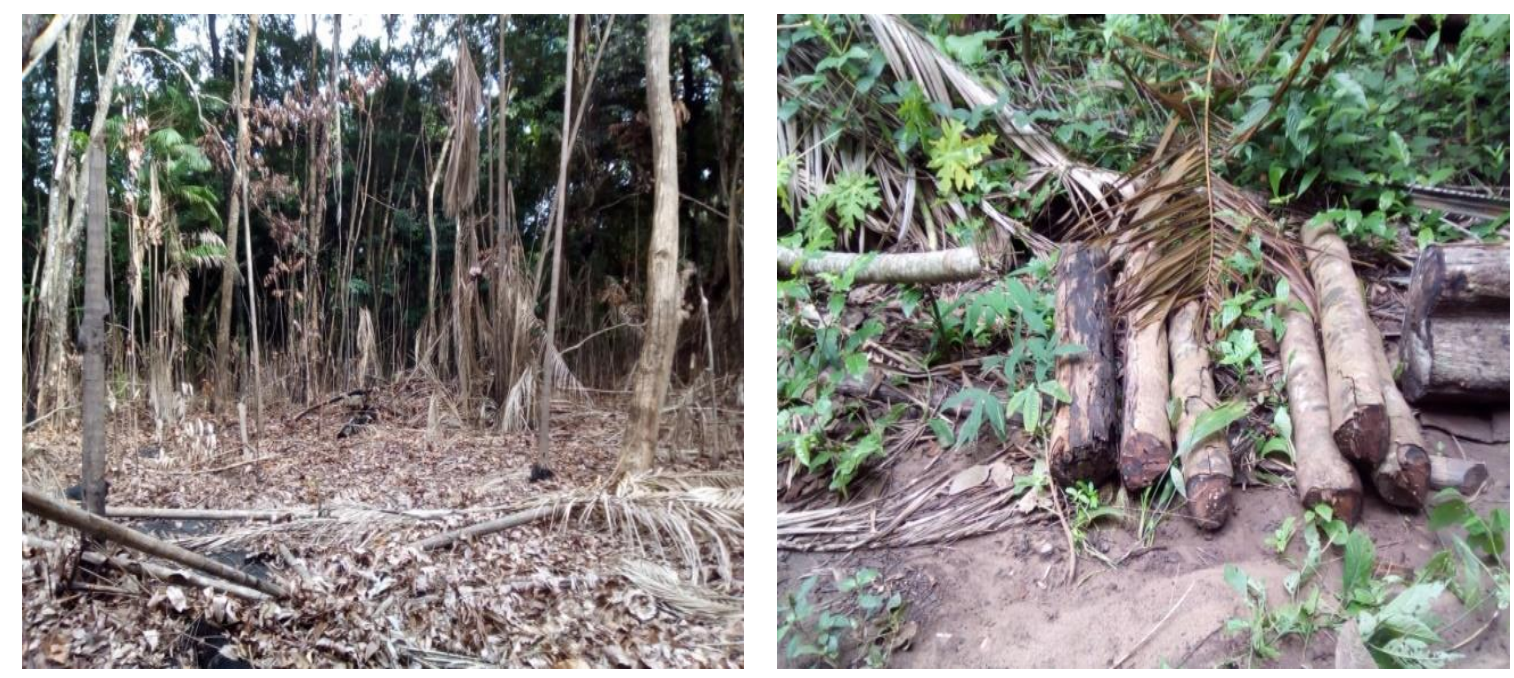

Fonte: Registro de Pesquisa (2017).

\section{CONCLUSÕES/RECOMENDAÇÕES}

Conclui-se que com o crescimento urbano de São Luís provocou impactos sobre APA do Itapiracó, com descarga de efluentes, retirada da vegetação, despejo de resíduos sólidos. Notou-se que com a falta de conhecimento da população e fiscalização dos órgãos competentes do município de São Luís e do estado. Possíveis soluções a ser tomadas: a proibição e fiscalização para que não haja mais o despejo de efluentes na APA, atenuar o crescimento dos bairros que se encontram as margens da APA na horizontal. Dessa maneira é pertinente o reconhecimento dos impactos ambientais, e associar a população com ações de educação ambiental.

\section{REFERÊNCIAS BIBLIOGRÁFICAS}

ARAÚJO, R. R; RANGEL M.E.S. crescimento urbano e variações térmicas em São Luís-MA. In: REVISTA GEONORTE, Edição Especial 2, V.2, N.5, p. 308-318, 2012. Acesso em 09/03/2017. 


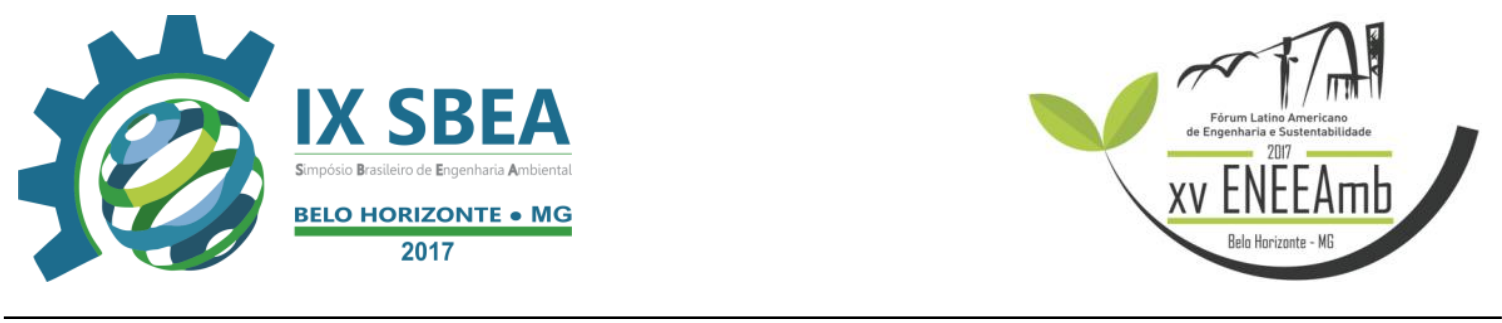

BRASIL. Lei 9605 de 12 de fevereiro de 1998. Dispõe sobre a proteção da vegetação nativa. Disponível em: < http://www.planalto.gov.br/ccivil_03/leis/L9605.htm >. Acesso em: 09/03/2017.

COSTA, N. F. A. et al. Efeitos da Urbanização na Área de Proteção Ambiental do Itapitacó, São Luís, MA. São Luís, 2008. Acesso em: 09/03/2017.

DECRETO 15.618 de 23 de junho de 1997. Criação na Área de Proteção do Ambiental do Itapiracó. São Luís. Disponível em: < https://documentacao.socioambiental.org/ato_normativo/UC/308_20100823_160320.pd f > . Acesso em: 09/03/2017.

ROCHA, E. C; CANTO, J. L; PEREIRA, P. C. Avaliação de impactos ambientais nos países do MERCOSUL. Ambiente e Sociedade. São Paulo, v. 8, n. 2, p. 148-160, jul./dez. 2005. Acesso em 05/03/2017.

SANTOS; L. E. N. dos. Expansão urbana e segregação socioespacial: faces da crise urbana em São Luís-MA. Disponível em: < http://simpurb2015.com.br/anais-2015/>. Acesso em: 09/03/2017. 